\title{
Pedigree and productive qualities of Obroshin grey and white gooses at their growing
}

\author{
M. Petriv, \\ Candidate of Agricultural Sciences \\ L. Sloboda, \\ N. Zagorets \\ Institute of Agriculture of the Carpathian region NAAS \\ O. Sloboda, \\ Candidate of Agricultural Sciences \\ Lviv National University of Veterinary Medicine and Biotechnology named after S. Gzyckyi
}

The purpose. Perfecting pedigree and productive qualities of Obroshin grey and white gooses at growing «in it». That has allowed saving valuable qualities of initial livestock. Methods. Selectionpedigree work was carried out with the use of instrumental methods and the newest recommendations concerning application of physiological and-biochemical markers of assessment of economically beneficial attributes, supervisory control of exterior indexes and methods of analysis of variance. Results. Experimentally is fixed that average egg production of gooses in I group made 41 pieces of eggs for a head, II $-40,5$, III $-38,6$, IV group $-38,1$ pieces of eggs. Average mass of an egg in I group made 160,1 g, II - 162,4, III - 153,2, IV - 159,1 g. Breeding fficiency of eggs was above at gooses of I group - 84,3\%. The maximum hatchability had gooses of II group - $76,5 \%$. Preservation of young birds in I group was the best and made $92 \%$. Conclusions. By results of slaughter it is determined that mixed Obroshin white gooses predominated above coevals by preslaughter alive mass, mass of viscerated carcass and edible parts of a body.

Key words: gooses, egg production, breeding efficiency, hatchability, preservation of young birds, dressing percentage.

Nowadays poultry farming is the largest supplier of valuable animal protein, the role of which is very important in human nutrition [4, 10]. The development of poultry farming depends largely on selection work aimed at improving productive and breeding properties, creating new breeds, lines and crosses of all kinds of poultry, as well as full and balanced feeding and implementation of new hightech technology.

The meat of young geese is high-calorie and delicious. A delicacy is the goose liver (foie gras), which is highly valued at the world market [1].

Even for pasture cultivation, the live weight of caterpillars already reaches $3.5-4 \mathrm{~kg}$ in the age of 810 weeks, and $4-4.5 \mathrm{~kg}$ in the case of intensive feeding, with the consumption of concentrated feed up to $3 \mathrm{~kg}$ per $1 \mathrm{~kg}$ of growth. The 8 - 9-week old geese contain a $17-18 \%$ protein, fat $-21-22 \%$. The energy value of the geese meat is determined from the calculation: $1 \mathrm{~kg}$ of edible part of the goose carcass contains 13.63 - $14.97 \mathrm{MJ}$ (3256 - $3576 \mathrm{kcal})[5,7]$.

The purpose of the research is to improve the tribal and productive properties of the prehistoric gray and white geese for breeding "in itself", which will enable to preserve the valuable properties of the initial population and, thus, to ensure their competitiveness in modern conditions. These studies were conducted through the selection of individuals with high productive properties for the purpose of obtaining the same type of poultry, which would correspond to the planned performance parameters under improved conditions of feeding and growing $[8,10]$. 
1. Scheme of the experiment, $n=100$

\begin{tabular}{|c|c|c|c|c|}
\hline q & Group I & Group II & Group III & Group IV \\
\hline$\sigma^{x}$ & $\begin{array}{c}O G \\
(O G \times B C) 0^{x}\end{array}$ & $\begin{array}{c}\text { OW } \\
(\mathrm{OW} \times \text { legart }) \mathrm{O}^{\circ}\end{array}$ & OG o & OW or \\
\hline 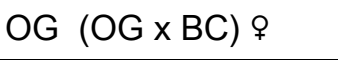 & $\mathrm{x}$ & & & \\
\hline OW (OW x legart) $q$ & & $\mathrm{x}$ & & \\
\hline OG $\$$ & & & $x$ & \\
\hline ОБWя & & & & $x$ \\
\hline
\end{tabular}

Note: OG - obroshynska grey; OW - obroshynska white; OG $q$ x BC $\sigma^{n}$, OW $\%$ legarto - the first generation.

Materials and methods of research: The research was conducted at the Laboratory of Small-scale Animal Husbandry of the Institute of Agriculture of the Carpathian Region of NAAS and the State Enterprise "Myklashiv" of the Pustomyty District of Lviv Oblast in 2013-2014.

The object of research was the young Obroshinsky white and gray geese, large gray and legit from incubation to 26 weeks of age. Selection work was carried out by the method of individual selection, aimed at fixing the standard for each group of characteristics. Before the beginning of the breeding season, males and females of all breed groups were individually evaluated by the exterior, the typical feather, live weight. During the productive period, on the group level, a fertility, evapotranspiration of the eggs, and the removal of the young were carried out. At the age of one day, a rigorous selection of caterpillars was conducted on the exterior. In the process of growing live-weight caterpillars, a lower mean value for a herd, at 9 and 26 weeks of age was discarded. On the basis of the usual features, the selection of geese with a predominantly developed meat form has been carried out in the absence of exterior defects, and the measurements of body elements associated with meat forms have been determined, and the preservation of young animals up to 9 weeks of age has been taken into account. [3, 9].

Of the available on-farm population of geese, four groups of birds were formed in 100 head. In each group, which for the period of frying and oviposition (January-May) were partially at the proper level of feeding and retention. Holding was carried out daily with the calculation of the egg form index by a method of linear measurement, weighing and selection for this indicator and their mass for incubation. The hatching eggs were harvested and monitored for at least 14 days, after which the eggs were sent to an incubation which was carried out in accordance with the relevant instructions. Materials of research were processed by the method of variation statistics on the basis of the calculation of the arithmetic mean (M), the mean square error $(\mathrm{m})$ [4].

The young, starting at 1-day age, were labeled and separated for cultivation in accordance with the genotype (Table 1).

From 1 to 21 weeks of age, caterpillars were fed a feed by specially designed recipe [6] (Table 2).

Biologically active substances - vitamins and micronutrients were added to the compound feed in the premix. 1 ton of feed was added to the vitamins: 
2. Recipes for mixed fodder for caterpillars of experimental groups, $\%$

\begin{tabular}{|l|c|c|}
\hline \multirow{2}{*}{\multicolumn{1}{|c|}{ Components, \% }} & \multicolumn{2}{|c|}{ Age in weeks } \\
\cline { 2 - 3 } & $1-3$ & $4-12$ \\
\hline Knead the corn & 24 & 24,5 \\
\hline Knead is wheat & 30,3 & 35,3 \\
\hline Knead barley & 15 & 15 \\
\hline Sunflower oil & 12 & 5 \\
\hline Yeast Forage & 10 & 7 \\
\hline Fishmeal & 3 & 4 \\
\hline Meat and bone meal & 1 & 2 \\
\hline Bone meal & 1 & 1 \\
\hline Sault & 0,2 & 0,2 \\
\hline Chalk & 2,5 & 2 \\
\hline Feed fat & - & 3 \\
\hline Premix & 1 & 1 \\
\hline Together:\% & 100 & 100 \\
\hline
\end{tabular}

A-10 mlno; D3 -1.5 mlno; B1 -1g; B2-2g; B3-10g; B4-500g; trace elements: Mg - 50g; Zn - $50 \mathrm{~g}$; $\mathrm{Cu}-2.5 \mathrm{~g}[6]$.

The nutritional value of compound feed, depending on age, was: at the age of 1-3 weeks $283 \mathrm{kcal}$ OE and $19.9 \%$ crude protein, 4 to 12 weeks $280 \mathrm{kcal}$ OE and $18.4 \%$ crude protein.

The research was conducted using instrumental methods and recommendations for the use of physiological and biochemical markers for the evaluation of economically useful features, control of exterior characteristics and methods of variation statistics [2].

Research results: It was found that the live weight of adult poultry at the beginning of the egg was: females of the OS - $6.25 \mathrm{~kg}$, OB - 6.35, OS (OS $\times \mathrm{BC})$ $9-6.45$, OB (O.S. $\times$ Legart) $9-6,5$; males OS $7,15 \mathrm{~kg}, \mathrm{OB}-7,35$, OS (OS $\times \mathrm{BC}) \sigma^{7}-7,45$, OB (O $\times$ legart) $o^{x}-7,50 \mathrm{~kg}$.

Insecurity is an important indicator of productivity, which depends on the breed and individual peculiarities of the bird, the conditions of abstinence and feeding.

One of the important indicators in the evaluation of productive and tribal properties is the weight of the egg, which is related to puberty, age, fertility, incubation properties of eggs and live weight of young animals at 1-day age.

So, the duration of oviposition and the number of eggs dropped and the group prevailed other groups. However, the geese and groups were to a lesser extent dominated by geese of other groups by weight and size of eggs.

Average weight of geese and group was 41 pcs. eggs on the head, in the ii group - 40.5, yii - 38.6, group IV - 38.1 pcs. eggs At the same time, the average weight of eggs in the group was $160.1 \mathrm{~g}$, in ii - 162.4, and 153.2, IV - $159.1 \mathrm{~g}$. 
3. Dynamics of live weight of experimental goose $(m \pm m), k g$

\begin{tabular}{|c|c|c|c|c|c|}
\hline \multirow{3}{*}{ Group } & \multicolumn{5}{|l|}{ Age } \\
\hline & 1 день & 4 тижні & 9 тижнів & 12 тижнів & $\begin{array}{l}21 \\
\text { тиждень }\end{array}$ \\
\hline & \multicolumn{5}{|l|}{ Male } \\
\hline I & $0,101 \pm 0,016$ & $1,78 \pm 0,12$ & $4,32 \pm 0,23$ & $5,00 \pm 0,26$ & $5,37 \pm 0,26$ \\
\hline II & $0,104 \pm 0,20$ & $1,84 \pm 0,15$ & $4,61 \pm 0,24$ & $5,37 \pm 0,24$ & $5,81 \pm 0,26$ \\
\hline III & $0,103 \pm 0,014$ & $1,58 \pm 0,13$ & $4,05 \pm 0,25$ & $5,01 \pm 0,29$ & $5,31 \pm 0,20$ \\
\hline \multirow[t]{2}{*}{ IV } & $0,100 \pm 0,021$ & $1,53 \pm 0,13$ & $3,90 \pm 0,27$ & $4,71 \pm 0,25$ & $5,01 \pm 0,27$ \\
\hline & \multicolumn{5}{|l|}{ Female } \\
\hline I & $0,098 \pm 0,011$ & $1,76 \pm 0,14$ & $3,84 \pm 0,27$ & $4,63 \pm 0,23$ & $5,08 \pm 0,24$ \\
\hline II & $0,099 \pm 0,019$ & $1,81 \pm 0,15$ & $4,16 \pm 0,26$ & $4,98 \pm 0,25$ & $5,46 \pm 0,27$ \\
\hline III & $0,097 \pm 0,023$ & $1,47 \pm 0,14$ & $3,67 \pm 0,27$ & $4,60 \pm 0,27$ & $4,75 \pm 0,28$ \\
\hline IV & $0,097 \pm 0,017$ & $1,43 \pm 0,13$ & $3,59 \pm 0,22$ & $4,25 \pm 0,23$ & $4,59 \pm 0,2 \pm 3$ \\
\hline
\end{tabular}

Along with weighing, the length, width and egg form index were determined daily. These indices in and in the group were: egg length $-84.1 \mathrm{~mm}$, width $-56.2 \mathrm{~mm}$, form index - 66.8; in the ii group - 84.4, 56.1 and 66.5 respectively; in iiii - 83.2, 56.4, 67.5; in IV - 84 mm, $56.5 \mathrm{~mm}, 67.3$.

The results of studying the incubation properties of eggs indicate that the fertility rate was higher in the goose and the group and amounted to $84.3 \%$, which is $0.8 \%$ higher than in this group, in the group ii $-83.9 \%$, which is $0.9 \%$ higher than in the $\mathrm{V}$ group. Higher vividness was characterized by geese and groups - 76,5\%. this indicator was: in and in the group - 75,1\%, and iii - 71 and IV $-75,2 \%$. One of the indicators of the survival of young geese is its conservation during the growing season. From the data obtained, it is evident that the youth's safety in the group was better and was $92 \%$; uii91,8 ; ii-87; ulV-89\%. Therefore, the group also prevailed as a result of fertility and preservation indices.

According to our studies, the mass of caterpillars for the first day did not differ significantly (Table 3). At 4 weeks of age, this indicator was higher in the caterpillars of the li group and was: $1.84 \mathrm{~kg}$ males and $1.81 \mathrm{~kg}$ females. The same trend was observed at 9, 12 and 21 weeks of age: males $4.61,5.37$ and $5.81 \mathrm{~kg}$, females $4.16,4.98$ and $5.46 \mathrm{~kg}$, respectively.

For a more complete description of the productive properties of geese at 9 weeks of age, a slaughter was carried out, which resulted in the determination of the morphological composition of the carcass and the outbreak.

Analyzing the data of the slaughter, it should be noted that the geese and groups on all indicators dominated the geese of other groups: before the death of the live weight: males - $4590 \mathrm{~g}$, females $4152 \mathrm{~g}$; the weight of the caraway patrona: males - $3001 \mathrm{~g}$, females $-2690 \mathrm{~g}$; slaughter:

in males $-65.4 \%$, in females $-64.8 \%$; the weight of the male parts of males is $2,226 \mathrm{~g}$, females are $2,448 \mathrm{~g}$; the output of edible parts: in males $-59,4 \%$, females $-58,9 \%$. 


\section{Conclusions}

Obroshynski gray goose are characterized by the following performance indicators: weight 38.6 pcs. on the head; weight of eggs - $153.2 \mathrm{~g}$; fertility rate $-83,5 \%$; Output $-71 \%$; the live weight of geese at 9 weeks of age: males $-4.05 \mathrm{~kg}$, females - $3.67 \mathrm{~kg}$; preservation - $87 \%$. The locally-sprayed gray geese species are characterized by higher rates: by weight - by $6.2 \%$; fertility rate $-0,8 \%$; vividness $-4,2 \%$; the live weight of geese at 9 weeks of age: males - by $6.7 \%$, females - 4.6 ; Preservation - $5 \%$; for a higher weight of eggs by $4.5 \%$. Productivity of white horse-goose is characterized by the following performance indicators: weight-bearing - $38.1 \mathrm{pcs}$. on the head; weight of eggs - $159.1 \mathrm{~g}$; fertility - $83 \%$; withdrawal rate $-72.5 \%$; the live weight of geese at 9 weeks of age: males - $4.14 \mathrm{~kg}$, females - $3.59 \mathrm{~kg}$; preservation - 89\%. The locally-sprayed white goose had higher performance: by weight - by $6.3 \%$; fertility - $0.09 \%$; Output - $4 \%$; the live weight of the population in the 9-week-old age: males - by $11.3 \%$, females - $15.8 \%$; Preservation $-2.8 \%$; for the highest weight of eggs - by $2.1 \%$. According to the results of the slaughter, it was determined that the homozygous white goose prevails over the peasants for pre-slaughter live weight, the weight of the carcasses and the edible parts of the body.

\section{Bibliography}

1. Belinsky I. Guinea pig of Hungary / I. Belinsky // Poultry farming. - 1986. - No 12. - P. 38-39.

2. Instructions for a comprehensive assessment of the breeding qualities of poultry (eggs and meat chickens, geese, ducks, turkeys, guinea fowls) / Ya.S. Royer, AD Davtyan, AV Egorova and others Sergiev Posad: VNITIP, 2007. - 28 p.

3. Lebedev P.T. Methods of study of corns, organs and tissues of animals / P.T. Lebedev, A.T. Usovich - Moscow: Rosselkhozizdat, 1976. - 428 pp.

4. Plohinsky N.A. Guide for biomaterials for livestock / N.A. Plokhinsky - M .: Kolos, 1969. - 256 p.

5. Breeding and fattening geese (method of rekom.) / In-t of agriculture and livestock in the near-by region of UAAS. - Lviv - Oboshyno, 2005 - 30 pp.

6. Sverzhentsov Al Programs of normal feeding of the bird / A.I. Freshmen - Dnipropetrovsk: ArtPress, 2008. - 160 p.

7. Sloboda O.M. Features of growing geese-broilers in the conditions of private and farm farms / O.M. Sloboda, L.Ya. Sloboda // Mater. International Sciences. Prakt.konf. - Kamyanets-Podolsk, 2009. - P. 142 - 143.

8. Tiller X. Directly regulated egg mass / X. Tiller // Poultry farming. - 1992.-No9.-C.28.

9. Fisinin VI Assessment of the quality of feed, organs, tissues, eggs and poultry / VI. Fisinin, AN Tishchenko, H.A. Egorov // Method. VNITI leadership. - Sergiev Posad, 1998. - 114 p.

10. Sharkova I. Geneous fund of geese / I. Sharkova // Poultry farming. - 1990. - No 8. - S. 29 - 30. 